\title{
PERCEIVING OWN AND OTHERS BEHAVIOUR: AN EXPLORATION IN SOCIAL PERCEPTION
}

\author{
Ran Bijay Narain Sinha \\ Magadh University \\ Arif Hassan* \\ International Islamic University Malaysia
}

\begin{abstract}
The paper reports the findings of a study conducted to find differences in self-perception with perception of others in order to identify a culturally sensitive method to explore social reality. The instruments measured how respondents rate themselves or others on several negative and positive descriptions of thoughts and behaviours. A sample of 100 respondents from diverse background in India rated predominantly positive and negative description of beliefs, values and preferences twice -- first for the people residing around them and then for themselves. They also rated themselves on a scale of social desirability. The findings confirmed that they attributed negative cognitions (beliefs, values and preferences) to the others more than themselves but attributed predominantly positive beliefs, values and preferences to themselves. The social desirability orientation was significantly related to respondents' self but not to others' perception. The findings thus suggested the use of informants rather than respondents in social research especially on sensitive issues such as ethical and moral behaviour.
\end{abstract}

Keywords: Social Research; Social Desirability Effect; Response Bias; Informants Method.

\section{INTRODUCTION}

"Man is least himself when he talks in his own person. Give him a mask, and he will tell you the truth." - Oscar Wilde

There has long been a controversy in social sciences that whether an individual or the group should be the basic unit of analysis to understand the social reality. The western thinkers (e.g. Hogan, 1975; Spence, 1985) have adopted the individual as the basic unit of analysis to interpret the nation, culture and psychological reality. A different view emphasizes that the collective determines and explains the psychological make-up of an individual (Brodbeck, 1976; Hsu, 1972). Earlier, Allport (1924) asserted that "There is no psychology of groups which is not essentially and entirely a psychology of individuals" (Allport, 1924, p.4). G. W. Allport (1968) advanced this individualistic tradition to study the conscious motivations of individuals. $\mathrm{He}$ emphasized a rational approach seeking consistency in the complexity of human behaviour. It was argued that Individuals are conscious of their cognitions and motivations and are rational in their behaviour.

\& Corresponding Author: Dept. of Business Administration, International Islamic University Malaysia, PO Box 10, 50728 Kuala Lumpur, Malaysia. E mail: arifh@iium.edu.my 
Following this individualistic tradition, Edwards (1957) contended that "It might seem logical to assume that if we want to know how individuals feel about some particular psychological object; the best procedure would be to ask them directly" (p. 3). Once the individualistic foundation was well laid out, even the social reality was conceptualized as a totality of how individuals conceive it. A number of scholars (e.g. Hogan, 1975; Spence, 1985) studied macro level societal phenomena from this individualistic perspective. Hofstede (1980), for example collected responses of IBM employees in a large number of cultures, aggregated them into cultural scores, and extracted the dimensions to compare the cultures.

Despite such a strong tradition presuming the validity of individualistic approach, there were voices of skepticism even in the West that remained largely unattended in the psychological research. Edwards (1957), for example, had admitted "the reluctance of many individuals to give public expression to their feelings or attitudes on controversial issues..." (p.3). Triandis (1980) further cautioned,

"Respondent methods [where the subject is responding to stimuli presented by the researcher] are more obtrusive, and they are more likely to be distorted by reactivity. The respondents are more likely to distort their answers, so that they will appear to be socially desirable people to the researcher, their peers, or the authorities in their culture or from the point of view of their culture's ideal." (p. 80)

If individuals' responses are susceptible to social desirability effects in an individualistic culture in the USA, they are likely to be much more tailored in a collectivist culture where people identify themselves in terms of collectives, comply with social norms rather than individual attitudes, yield personal goals to those of the collectives, and prioritize relationships over rationality (Triandis, 1995). The cultural ideal that Triandis referred above requires that respondents present themselves in a socially desirable fashion. A number of studies (Hofstede, 1980; Sinha \& Verma, 1987) showed that Indian culture is by and large collectivist while others find that it is both collectivist and individualist (Sinha and Tripathi, 1990; Sinha, Sinha, Verma \& Sinha, 2001; Sinha, Vohra, Singhal, Sinha, \& Ushashree, 2002; Sinha, 2004).

Further, Sinha (2010) argued that a way out of the problem in investigating a social reality without getting it contaminated by social desirability is to place respondents in the role of informants. In informants' role, respondents are likely to distance themselves from their own personal views and make impersonal observations of the social reality. There is an additional rationale to do so. Because collectives, not individuals, are the core of social reality in a collectivist culture, it is more appropriate to ask respondents about the way they view collectives rather than they view themselves.

The issue pertaining to the relative merit of respondents versus informant's method is still far from settled because the arguments are still unsupported by a comparative evaluation of the two methods in a single study. Sinha (2010) has indeed reported substantial support in favour of the informant's method, but has not yet compared the two. The present study is an attempt in this direction. The paper reports the findings of two studies - one conducted in India on a sample drawn from a mix of social population, and the other conducted in Malaysia on a student sample. 
The discussion above suggests that the respondents' self-perception compared to their perception of the people at large will be affected by the cultural pressure to give socially desirable responses. It means their self-perception will be over rated for positive and under rated for negative beliefs, preferences, and practices. Thus the following hypothesis has been formulated:

Hypothesis 1: Respondents endorse more strongly positive beliefs, preferences, and practices for themselves than for the people in their society. The reverse is true for negative beliefs, preferences, and practices, which is attributed more strongly to people than self

However, there may be a positive relationship between how respondents view themselves and people in their society. Collectivism is known for the inter-dependence of self (Markus \& Kitayama, 1991) and interconnectedness among people. To the extent that Indians and Malaysians are collectivists, they are likely to perceive themselves connected to others that in turn might lead to see similarity between themselves and other people. Respondents, therefore, may project their own positive as well as negative beliefs, preferences, and practices to them. In order to test it, the following hypothesis is advanced:

Hypothesis 2: Respondent's perception of their beliefs, preferences, and practices are correlated with their perception of people's beliefs, and preferences.

Because the social desirability effects are presumed to be the bone of contention, the respondents who are high on the disposition to present them in socially desirable fashion are likely to overrate their positive and underrate their negative beliefs, preferences, and practices. There is, however, no ground to believe that respondents' social desirability disposition will affect how they perceive other people. Hence, the following hypothesis:

Hypothesis 3: Respondents'scores on a social desirability measure are positively correlated with their score on the positive beliefs, preferences, and practices and negatively correlated with the negative beliefs, preferences, and practices. The social desirability measure is uncorrelated with respondents 'perception of people's positive and negative beliefs, preferences, and practices.

\section{METHOD}

\subsection{The Context and the Sample}

This study was conducted in India. A sample 100 adults representing a mix population participated in the study. They belonged to educated urban middle class, representing the age range of 20 to 60 years $($ Mean $=40.38)$. Seventy per cents of them were males and $74 \%$ were married. And $61 \%$ were having either a graduate or post graduate degree.

\subsection{Measures}

A questionnaire consisting of items in three parts was prepared. It measured the following: 


\subsubsection{Perception of people's beliefs, preferences, and practices}

While selecting a measure for people's beliefs, preferences, and practices, care was taken to safeguard against a possibility that the items may be stereotypical. Hence, 15 statements describing people's discrepant beliefs, preferences, and practices were drawn from a study (Sinha, et al., 2010) in which a large sample of adults located at 12 different parts of India were involved. These 15 statements were the ones which had the highest mean scores indicating that they mapped socio-typical rather than stereotypical responses. Respondents were asked to rate each statement on a 5-point scale ranging from Quite False (1), False (2), Undecided (3), True (4), to Quite True (5). Because the statements had discrepant ideas having both positive and negative themes, a 9-member social scientists group was involved in sorting them as either predominantly positive or predominantly negative. Six statements were judged having predominantly positive theme. Two examples were the following:

- People believe in destiny but struggle hard to succeed in life.

- People know when to remain silent and when to say what.

Of the remaining 11 statements, eight were unanimously judged to have predominantly negative theme while one statement was categorised negative based on the majority judgment. One example of unanimous and one of majority decision were as follows;

Unanimously negative:

- People talk ideals but behave in selfish manners.

- People are concerned about what others think of them.

\subsubsection{Self-perception}

In order to compare respondents' perception of people and themselves, the same 15 statements that were used for perceiving people were rephrased to measure respondents' perception of their own beliefs, preferences, and practices. Again the same 5-point scale was employed. The examples of rephrased statements were following:

Positively worded items:

- I believe in destiny but struggle hard to succeed in life.

- I know when to remain silent and when to say what.

- Negatively worded items:

- I talk ideals, but behave in selfish manners.

- I am concerned about what others think of me.

\subsubsection{Social Desirability}

Items from the shorter a version of the Crowne-Marlow Scale (Fischer \& Fick, 1993) were modified to measure the degree of respondents' disposition to present themselves in a socially desirable fashion. The measure consisted of 12 items including three negatively worded items. The items were rated on the same 5-point scale ranging from Quite False (1), False 
(2), Undecided (3), True (4), to Quite True (5). Factor analysis by the principal component analysis with the varimax solution yielded only one factor on the criterion that the Eigenvalue should not be less than one. The nine items out of 12 that loaded on the factor profiled a person with high disposition of social desirability as the one who forgives those who hurt him, always admits when he is wrong, does not speak a lie, does not get angry even he is provoked, is always courteous even to disagreeable people, never offends others, and always helps someone in trouble. The alpha coefficient ( $\mathrm{rii}=.66$ ) was acceptable. The factor accounted for $20.21 \%$ of variance. Four examples of the high loading items were the following:

- I forgive those who hurt me (Factor loading .63)

- I always admit when I am wrong (Factor loading .60)

- I do not speak a lie (Factor loading .59)

- I do not get angry even if I am provoked (Factor loading .71)

To examine the measure of social responsibility, four items were also included in Part 3 measuring on the same 5-point scale the respondent self-perception that he/she was a successful person, a spiritual person, satisfied with life, and had the capacity to solve difficult problems of life. All items loaded on a single factor, labeled as Personal Well-being. It explained $49.48 \%$ of variance. (Alpha =.78). A positive correlation between the wellbeing and social desirability would support the validity of the latter. Two examples of the high loading items were the following:

- I am satisfied with my life (Factor loading .75)

- I am successful person (Factor loading .71)

\subsubsection{Background information}

Information regarding age, education, and economic class (low middle class, middle-middle class, high middle class, and high class) were also collected for describing the sample of respondents and exploring whether they have any impact on respondents' perceptions of themselves and the people at large.

\section{RESULTS}

\subsection{Perception of Predominantly Positive Statements}

Each of the six predominantly positive statements was compared for the respondents' perception of themselves and that of the people living around them. Table 1 revealed two striking features. First, out of six, five statements were reported to have higher mean scores for self than for people, of which three were statistically significant. The results thus confirmed a trend to manifest stronger endorsement of positive beliefs, preferences, and practices for self than for others.

Second, almost all coefficients of correlation between self and people's perception were either highly $(p<.001$ or .01$)$ or moderately $(p<.05)$ significant. It seems that the respondents did project their own positive beliefs, preferences, and practices to the people residing around 
them. The one exception that emerged was the item, "Sense what others mean and intend" that was uncorrelated. The other three items where mean scores for self was higher than people were the following: 'Know when to remain silent and when to say what', 'watch out the mood of others before asking for a favour', 'forget differences and help each other during disasters', 'sense what others mean and intend' and 'becoming quite creative when get challenging opportunities'. All these items showed the social skills of the respondents. Table 1 presents the summary of the statistical findings.

Table 1: Mean Comparisons between 'People' \& 'Self' Ratings on Positive Themes

\begin{tabular}{|c|c|c|c|c|c|}
\hline Statements & Rating of & Mean & SD & $\mathbf{r}$ & $\mathbf{t}$ \\
\hline $\begin{array}{l}\text { Believe in destiny but struggle hard to } \\
\text { succeed in life }\end{array}$ & $\begin{array}{l}\text { People } \\
\text { Self }\end{array}$ & $\begin{array}{l}3.72 \\
3.65\end{array}$ & $\begin{array}{c}.94 \\
1.01\end{array}$ & $.22 *$ & .57 \\
\hline $\begin{array}{l}\text { Forget differences and help each other } \\
\text { during disasters }\end{array}$ & $\begin{array}{l}\text { People } \\
\text { Self }\end{array}$ & $\begin{array}{l}4.15 \\
4.28\end{array}$ & $\begin{array}{l}.85 \\
.79\end{array}$ & $.26^{* *}$ & 1.31 \\
\hline $\begin{array}{l}\text { Become quite creative when get } \\
\text { challenging opportunities }\end{array}$ & $\begin{array}{l}\text { People } \\
\text { Self }\end{array}$ & $\begin{array}{l}3.75 \\
4.02\end{array}$ & $\begin{array}{l}.94 \\
.86\end{array}$ & $.25 * *$ & $2.45^{*}$ \\
\hline $\begin{array}{l}\text { Know when to remain silent and when } \\
\text { to say what }\end{array}$ & $\begin{array}{l}\text { People } \\
\text { Self }\end{array}$ & $\begin{array}{l}2.90 \\
3.86\end{array}$ & $\begin{array}{l}1.07 \\
.98\end{array}$ & $.24 * *$ & $7.60 * * *$ \\
\hline $\begin{array}{l}\text { Watch out the mood of others before } \\
\text { asking for a favor }\end{array}$ & $\begin{array}{l}\text { People } \\
\text { Self }\end{array}$ & $\begin{array}{l}3.46 \\
3.87\end{array}$ & $\begin{array}{l}.98 \\
.95\end{array}$ & $.19^{*}$ & $3.35 * *$ \\
\hline Sense what others mean and intend & $\begin{array}{l}\text { People } \\
\text { Self }\end{array}$ & $\begin{array}{l}3.22 \\
3.68\end{array}$ & $\begin{array}{l}.97 \\
.96\end{array}$ & .13 & $3.60 * * *$ \\
\hline
\end{tabular}

Notes: $* \mathrm{p}<.05, * * \mathrm{p}<.01,{ }^{* * *} \mathrm{p}<.001$

\subsection{Perception of Predominantly Negative Statements}

In contrast to the positively worded statements, the respondents rated all nine negative statements more true for the people than for themselves, the differences were highly significant $(\mathrm{p}<.001)$ for seven of them (Table 2). In general, the respondents perceived that the people around them, but not they, run after power and positions, although value peace of mind, talk ideals, but behave in selfish manners, make promises, but give excuses for not keeping them, believe in science but are superstitious in behaviour, work very hard when expect to get amply rewarded, throw garbage at public places, though keep own premises clean, and hide intentions and behave in socially desirable ways.

Another interesting contrast from the preceding finding was that, compared to five out of six significant positive coefficients of correlation, there was only one negative statement, "Work very hard when expect to get amply rewarded" that was significantly $(\mathrm{p}<.01)$ correlated. The 
decision to consider it negative was not unanimous, because some of the group members involved in classifying the items felt that both hard work and rewards are essentially positive, although its linkage hinges on a kind of opportunistic motive. Table 2 presents the summary of the statistical findings.

Table 2: Mean Comparisons between 'People' \& 'Self' Ratings on Negative Themes

\begin{tabular}{|c|c|c|c|c|c|}
\hline Statements & Rating of & Mean & SD & $\mathbf{r}$ & $\mathbf{t}$ \\
\hline $\begin{array}{l}\text { Run after power and positions although } \\
\text { value peace of mind }\end{array}$ & $\begin{array}{l}\text { People } \\
\text { Self }\end{array}$ & $\begin{array}{l}4.18 \\
3.28\end{array}$ & $\begin{array}{l}.61 \\
1.27\end{array}$ & .05 & $6.51 * * *$ \\
\hline $\begin{array}{l}\text { Talk ideals but behave in selfish } \\
\text { manners }\end{array}$ & $\begin{array}{l}\text { People } \\
\text { Self }\end{array}$ & $\begin{array}{l}4.11 \\
2.35\end{array}$ & $\begin{array}{l}.71 \\
1.01\end{array}$ & .03 & $14.48 * * *$ \\
\hline $\begin{array}{l}\text { Make promises, but give excuses for } \\
\text { not keeping them }\end{array}$ & $\begin{array}{l}\text { People } \\
\text { Self }\end{array}$ & $\begin{array}{l}3.90 \\
2.80\end{array}$ & $\begin{array}{c}.93 \\
1.09\end{array}$ & .18 & $8.47 * * *$ \\
\hline $\begin{array}{l}\text { Believe in science but are superstitious } \\
\text { in behavior }\end{array}$ & $\begin{array}{l}\text { People } \\
\text { Self }\end{array}$ & $\begin{array}{l}3.76 \\
3.09\end{array}$ & $\begin{array}{l}1.07 \\
1.16\end{array}$ & .07 & $4.41 * * *$ \\
\hline $\begin{array}{l}\text { Work very hard when expect to } \\
\text { get amply rewarded }\end{array}$ & $\begin{array}{l}\text { People } \\
\text { Self }\end{array}$ & $\begin{array}{l}4.04 \\
3.72\end{array}$ & $\begin{array}{l}.88 \\
1.07\end{array}$ & $.31 * *$ & $2.77 * *$ \\
\hline $\begin{array}{l}\text { Throw garbage at public places, though } \\
\text { keep own premises clean }\end{array}$ & $\begin{array}{l}\text { People } \\
\text { Self }\end{array}$ & $\begin{array}{l}4.10 \\
2.29\end{array}$ & $\begin{array}{c}.95 \\
1.13\end{array}$ & -.05 & $11.99 * * *$ \\
\hline $\begin{array}{l}\text { Hide intentions to behave in socially } \\
\text { desirable ways }\end{array}$ & $\begin{array}{l}\text { People } \\
\text { Self }\end{array}$ & $\begin{array}{l}3.81 \\
2.90\end{array}$ & $\begin{array}{l}.81 \\
1.07\end{array}$ & -.05 & $6.60 * * *$ \\
\hline $\begin{array}{l}\text { Concerned of what others think of } \\
\text { them } / \text { me }\end{array}$ & $\begin{array}{l}\text { People } \\
\text { Self }\end{array}$ & $\begin{array}{l}3.64 \\
3.50\end{array}$ & $\begin{array}{c}.93 \\
1.13\end{array}$ & .08 & 1.00 \\
\hline $\begin{array}{l}\text { Have knack to figure out who can be } \\
\text { useful in future }\end{array}$ & $\begin{array}{l}\text { People } \\
\text { Self }\end{array}$ & $\begin{array}{l}3.41 \\
3.23\end{array}$ & $\begin{array}{l}.98 \\
.92\end{array}$ & .07 & 1.39 \\
\hline
\end{tabular}

Notes: ${ }^{*} \mathrm{p}<.05,{ }^{* *} \mathrm{p}<.01,{ }^{* * *} \mathrm{p}<.001$

\subsection{Comparison of Positive and Negative Perceptions of the Self and People}

Before comparing the positive and negative statements for the self and others (people), it was of interest to check that the items within four of them had consistency. Alpha coefficients indicated that all four of them, ranging from .55 to .60 , approximated the generally acceptable level of .60. Hence, respondents' scores were separately pooled, averaged, and compared to a paired t-test in order to find out the significant differences in the perception of positive and negative statements attributed to the self and other people. The findings are reported in Figure 1. 
Figure 1: Self And People Perception On Positive And Negative Themes

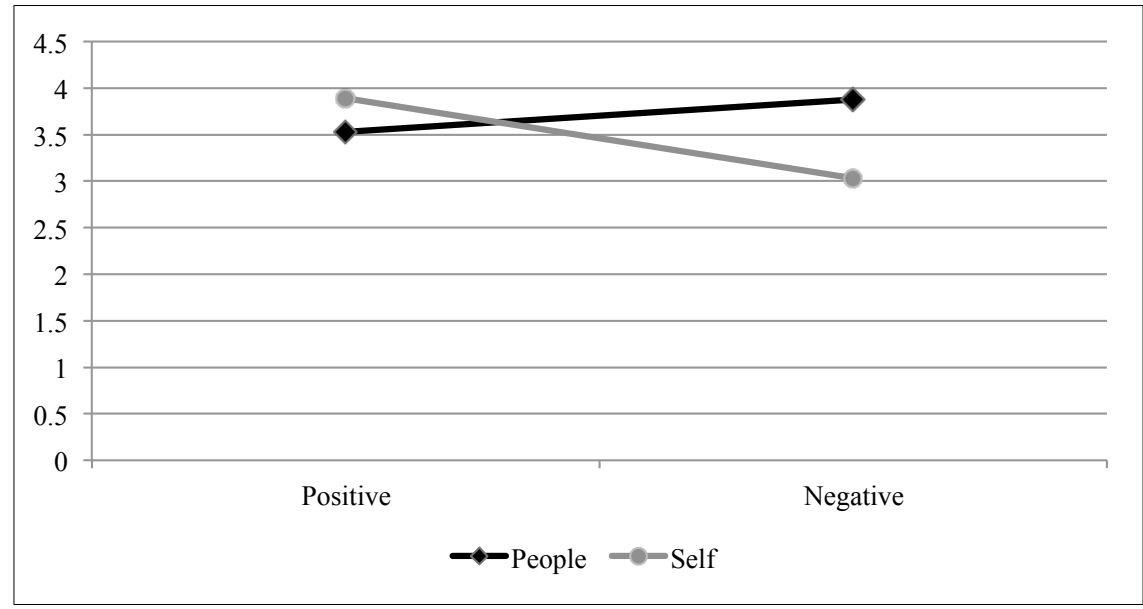

The tests of significance showed that positive statements were rated significantly higher than negative statements for both themselves and people $\left(t_{s}=14.20 \& 5.45, p=00\right.$ respectively). Although the respondents rated themselves $(X=3.91, \mathrm{SD}=.48)$ a shade higher than other people $(\mathrm{X}=3.87, \mathrm{SD}=.38)$ on positive statements, the difference was not significant $(t<.01, d f$ $=99, p=.33$ ). Figure 1 revealed a much more pronounced difference occurred in the ratings of the negative statements for themselves and people. In other word, the respondents considered the negative statements much less true for themselves than for the people around them. There was probably a social desirability effect.

\subsection{Social Desirability and Other Correlates of Self and People's Perceptions}

The analysis further revealed that the social desirability disposition was not correlated to the people's perceptions of either positive statements $(r=.08, p>.05)$ or for the negative statements $(r=.01, p>.05)$. It was moderately correlated to both positive $(r=.24, p<.05)$ and negative $(r=-.21, p<.05)$ statements about the respondents themselves. In other words, respondents' disposition to present themselves in socially desirable fashion indeed led, though moderately, to attribute positive statements as more true and the negative statements as less true. Respondents' sense of wellbeing was unrelated to all other variables. More educated respondents were less negative about themselves. Older and more educated respondents gave more socially desirable responses $\left(r_{s}=.28 \& .32, p<.01\right)$.

\section{DISCUSSION}

The significant methodological indigenization introduced by Sinha was putting respondents in the role of informants and asking them to view social reality by distancing themselves from their own individual propensities. Sinha and his co-workers (see Sinha, 2010 for details) reported a number of studies that empirically proved the efficacy of this approach. The present study added further support by directly comparing the respondents and informants methods. It 
supported Sinha's contention that self-perception of people are moderated by their high social desirability disposition. It was found to be particularly true in rating negative statements for themselves (See Figure 1). The correlations were insignificant for the people's perception and significant for the respondents' self- perception.

Interestingly enough, the respondents gave higher ratings on the positive statements for both themselves and the people residing around them, although the average scores for themselves were a shade higher than for the people. (See Figure 1). There was also a significant positive correlation between the two. This partially supported Hypothesis 2 and suggested that the relationship culture induces people to see others in a positive light. One may even stretch Fiedler (1967) to argue that if a relationship oriented leader perceives even his least preferred co-worker favorably, there are possibilities the relationship oriented people see other people favorably too.

Unexpectedly, result demonstrated that the respondents' sense of well-being was unrelated to their social desirability score. It was expected that those who tend to present their socially desirable face will also report a higher level of wellbeing. However, older and better educated respondents reported higher levels of social desirability. Probably, the culture season those to remain socially wise.

Despite supportive evidence in favour of employing informant's method and items having discrepant ideas, there still exists a need to anchor the findings in actual behavior. Further studies are suggested to sample behaviours along with verbal measures to fill this gap.

\subsection{Implications for Studies in Social Sciences}

Most of the survey studies in social sciences employ respondents' method to collect data and the aggregated data are used to measure constructs and variables. To what extent the respondents are able to distance themselves from the social reality and provide true and objective response is debatable. Studies on moral/ethical values, religiosity, spirituality, work ethics, beliefs and practices, motivation, citizenship behavior, leadership styles and a host of other studies using self- report techniques may not yield objective data unless the respondents' are able to distance themselves and portray their true self. Using respondents as informants can be one option.

\section{REFERENCES}

Allport, F. H. (1924). Social psychology. Cambridge, MA: Riverside Press.

Allport, G. W. (1968). The historical background of modern social psychology. In G. Lindzey \& E. Aronson (Eds.), Handbook of social psychology (2 $2^{\text {nd }}$ ed) (pp. 1-80). Reading, MA: Addisson-Wesley.

Brodbeck, M. (1976). Methodological individualism: Definition and reduction. In J. O’Neill (Eds.), Modes of individualism and collectivism. London: Heinemann.

Edwards, A. L. (1957). The social desirability variable in personality assessment and research. New York: Dryden Press. 
Fiedler, F. E. (1967). A theory of leadership effectiveness, New York: McGraw-Hill

Fischer, D. G., \& Fick, C. (1993). Measuring Social Desirability: Short Forms of the MarloweCrowne Social Desirability Scale. Educational \& Psychological Measurement, 53, $417-$ 424.

Hofstede, G. (1980). Culture's consequences: International differences in work-related values. Beverly Hills, CA: Sage.

Hogan, R. T. (1975). Theoretical egocentrism and the problem of compliance. American Psychologist, 30, 533-540.

Hsu, F. L. K. (1972). Psychological anthropology (2nd ed.). Cambridge, MA: Schenkman.

Markus, H. R., \& Kitayama, S. (1991). Culture and the self: Implications for cognition, emotion, and motivation. Psychological Review, 98(2), 224-253.

Sinha, D., \& Tripathi, R. C. (1990). Individualism in a collective culture: A case of coexistence of dichotomies. Paper presented at the International Conference on Individualism and Collectivism: Psycho-cultural Perspectives from East and West, Seoul.

Sinha, J. B. P. (2010). Living and doing psychology. Psychology and Developing Societies, $22(1), 95-120$.

Sinha, J. B. P., \& Verma, J. (1987). Structure of collectivism. In C. Kagitcibasi (Eds.), Growth and progress in cross-cultural psychology. Lisse, Netherlands: Swets\&Zeitlinger.

Sinha, J. B. P., Singh, S., Gupta, P., Srivastava, K. B. L., Sinha, R. B. N., Srivastava, S., Ghosh, A., Siddiqui, R. N., Tripathi, N., Gupta, M., Mulla, Z., Vijayalakshmi, C., \& Pandey, A. (2010). An Exploration of the Indian Mindset. Psychological Studies, 55(1), 3-17.

Sinha, J. B. P., Sinha, T. N., Verma, J., \& Sinha, R. B. N. (2001). Collectivism coexisting with individualism: an Indian scenario. Asian Journal of Social Psychology, 4(2), 133-145.

Sinha, J. B. P., Vohra, N., Singhal, S., Sinha, R. B. N., \& Ushashree, S. (2002). Normative predictions of collectivist-individualist intentions and behaviour of Indians. International Journal of Psychology, 37(5), 309-319.

Sinha, R. B. N. (2004). Choice of the combinations of collectivist and individualist behaviour and intention as function of generation gap. Psychological Studies, 49(1), 14-19.

Spence, J. (1985). Achievement American Style: The rewards and costs of individualism. American Psychologist, 40(12), 1285-1295.

Triandis, H. C. (1980). Introduction. In H. C. Triandis \& W. W. Lambert (Eds.), Handbook of cross-cultural psychology. Boston: Allyn \& Bacon.

Triandis, H. C. (1995). Individualism and collectivism. Boulder, Co: West View Press. 